\title{
AODV Routing Protocol Modification With Dqueue(dqAODV) and Optimization With Neural Network For VANET In City Scenario
}

\author{
Soumen Saha ${ }^{1, a}$, Utpal Roy ${ }^{2}$ and D.D. Sinha ${ }^{3}$ \\ ${ }^{1}$ Department of CSE, University of Calcutta, Kolkata, West Bengal, India \\ ${ }^{2}$ Department of CSS, Siksha-Bhavana, Visva-Bharati, West Bengal, India \\ ${ }^{3}$ Department of CSE, University of Calcutta, Kolkata, West Bengal, India
}

\begin{abstract}
Vehicular ad hoc network (VANET) is considered as a sub-set of mobile ad hoc network (MANET). VANET can provide road safety by generating collision warning messages before a collision takes place, lane change assistance; can provide efficient traffic system by introducing cooperation among vehicles; and can also improves in infotainment applications like cooperative file accessing, accessing internet, viewing movies etc. It provides smart Transportation System i.e., wireless ad-hoc communication among vehicles and vehicle to roadside equipments. VANET communication broadly distinguished in two types; 1) vehicle to vehicle interaction, 2) vehicle to infrastructure interaction. The main objective of VANET is to provide safe, secure and automated traffic system. For this automated traffic techniques, there are several types of routing protocols has been developed. MANET routing protocols are not equally applicable in VANET. In the recent past Roy and his group has proposed several study in VANET transmission in [1-3]. In this study, we propose a modified AODV routing protocol in the context of VANET with the help of dqueue introduction into the RREQ header. Recently Saha et al [4] has reported the results showing the nature of modified AODV obtained from the rudimentary version of their simulation code. It is mainly based on packet delivery throughput. It shows greater in-throughput information of packet transmission compare to original AODV. Hence our proposal has less overhead and greater performance routing algorithm compared to conventional AODV. In this study, we propose and implement in the NCTUns-6.0 simulator, the neural network based modified dqueue AODV (dqAODV) routing protocol considering Power, TTL, Node distance and Payload parameter to find the optimal route from the source station (vehicle) to the destination station in VANET communications. The detail simulation techniques with result and output will be presented in the conference.
\end{abstract}

\section{Introduction}

For VANET the routing protocols works on adhoc basis and infrastructure basis in the network [Fig.1]. Where the ad-hoc network is highly unstable as vehicle's speed and lane change factors.

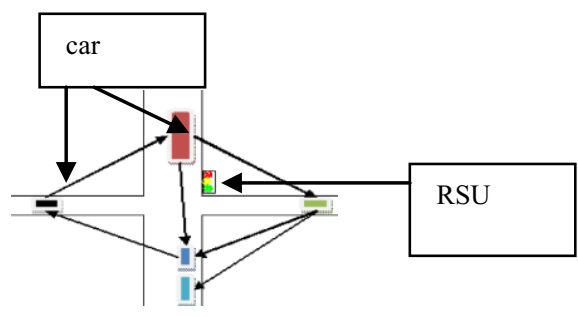

Fig.1. Ad-hoc VANET[5]

\subsection{Ad-hoc Routing protocols}

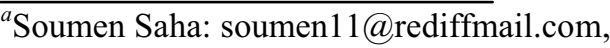

Ad-hoc routing protocol fist setup the path next exchange information with packets and take decision of runtime alternatives paths [6].

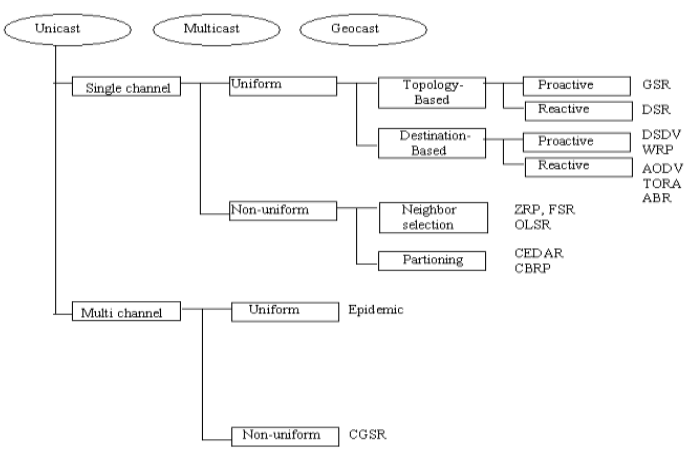

Fig.2.Classification of Ad-hoc Routing Protocols [6]

The topology based routing is classified [Fig2] in to three ways

-Proactive (table-driven) routing protocols.

-Reactive (on-demand) routing protocols. 
-Hybrid routing protocols (for both type).

\subsubsection{Proactive Routing}

Proactive routing protocols are based on shortest path first algorithms [6]. It maintains and update routing information's on routing in between all nodes of a supplied network at all times, even if the paths are not currently being used. Even if some paths are never used but updates for those paths are constantly broadcasted among nodes [6]. Route updates are periodically performed regardless of network payload, bandwidth constraints.

\subsubsection{Reactive Routing}

On demand or reactive routing protocols were planned to overcome the overhead problem, which was created by proactive routing protocols. Maintaining only those routes that are currently live and active [6]. These protocols implement route determination on a demand basis or need basis and maintain only the routes that are currently in use. Therefore it reducing the burden and overhead on the network when only a subset of available routes is in active at any point of time [6].

AODV maintains and uses an efficient method of routing, which reduces network burden by broadcasting route discovery packet mechanism and by runtime updating routing information at each adjacent node. Route discovery in AODV can be perform by sending RREQ (Route Request) from a node when it needs a route to send the data to a particular destination. After sending RREQ, a node waits for the RREP (Route Reply) and if it does not receive any RREP within time threshold.

The node members of contracted ad-hoc network when out of the range of the existing ad-hoc network, it may fails to progress. Hence, we need some other helping equipments (road side equipment) to help those node (Vehicle) to progress. But, irrespective of that, if we taken the existing neighbor Ad-hoc network, that can help to restart the communication with that isolate node(Vehicle), which is more economic, as we do not need any extra equipment or extra data communication.

\section{Proposed Work:}

Our previous proposed modified AODV routing protocol by implementing a dqueue (dqAODV)[7] is on the basis of packet collision, packet drop and in-out throughput. The fact is that when a intermediate node between source and destination gets some packet from the another node which had got from any other node will insert the node's IP to the generated dqueue instead of discarded. During unicast the RREP packet if any link is breakage, then this node pick out the another node from the created dqueue and re-unicast the RREP packet .

Proposed Artificial Intelligence Based Modified AODV Routing Protocol in VANET
In AODV protocol, a source station (vehicle) initiates a Route Request (RREQ) in the network for connecting to a destination station (node), the route is determined considering the four attributes or parameters like the distance (D), the overload or overhead (O), the consumption of electric power $(\mathrm{P})$, and the expected time (T) to remain the route in alive (active) condition. First three attributes $(\mathrm{D}, \mathrm{O}, \mathrm{P})$ are acceptable for lesser or minimum value and the fourth attribute expected time is accomplished for larger value, i.e., longer period. Therefore, the normalized expected time period is deducted from one (1) to bring homogeneity among all attributes. There may be different routes under AODV protocol available from the source station to the destination station having one set of values $\mathrm{D}, \mathrm{O}, \mathrm{P}$, and $\mathrm{T}$ for each route. Now the best AODV route is selected among the different routes by applying fuzzy neural network algorithm [8-10][11].

\subsection{Modified AODV Route Searching by Fuzzy Neural Network}

P.K. Bhattacharjee, et. Al [11] have propose a optimization technique of routing parameters using fuzzy neural network. According their aproch we have optimize the routing parameter for our experiment.

ASA1: The normalized value of a distance (d1) is equal to $D_{1} / D_{\max }$, where $D_{1}$ is the distance for a particular route, and $\mathrm{D}_{\max }$ is the maximum available distance among the all routes in the route discovery process. If the normalized route distance for a specific path is taken as $\mathrm{d} 1$, the membership functions of a fuzzy set F1 is defined as follows, $\mu_{\mathrm{F} 1}(\mathrm{a} 1)=\mathrm{d} 1$, hence, $\mathrm{F} 1=\{(\mathrm{a} 1, \mathrm{~d} 1)\}$.

ASA2: The normalized value of an Overhead (h1) is equal to $\mathrm{O}_{1} / \mathrm{O}_{\max }$, where $\mathrm{O}_{1}$ is the overhead or Overload for the specific route, and $\mathrm{O}_{\max }$ is the maximum available Overhead among the all routes in the route discovery process. If the normalized overhead value is taken as h1 for the particular route, The membership functions of a fuzzy set F2 is defined as follows, $\mu_{\mathrm{F} 2}(\mathrm{a} 2)=\mathrm{h} 1$, hence, F2 $=\{(\mathrm{a} 2, \mathrm{~h} 1)\}$

ASA3: The normalized value of consumed electric power (p1) is equal to $\mathrm{P}_{1} / \mathrm{P}_{\max }$, where $\mathrm{P}_{1}$ is the electric power consumed for the route, and $\mathrm{P}_{\max }$ is the maximum electric power consumed for a route in the route discovery process. If the normalized electric power consumed value is taken as $\mathrm{p} 1$ for the specific route, the membership functions of a fuzzy set F3 is defined as follows, $\mu_{\mathrm{F} 3}(\mathrm{a} 3)=\mathrm{p} 1$, hence, $\mathrm{F} 3=\{(\mathrm{a} 3, \mathrm{p} 1)\}$.

ASA4: The normalized value of a time $\left(t_{n}\right)$ available is equal to $T_{1} / T_{\max }$, where $T_{1}$ is the expected time allocated for the specific route, and $\mathrm{T}_{\max }$ is the maximum available expected time for a route in the route discovery process. Since the normalized available time is preferred for larger value; the normalized unavailable time (t1) which is favored for lesser value, is taken as the fourth 
attribute to bring the homogeneity with all other attributes, then $t 1$ is better for lesser value,

So, $\mathrm{t} 1=\left(1-\mathrm{t}_{\mathrm{n}}\right)$. If the normalized time is taken as $\mathrm{t} 1$ for the particular route, the membership functions of a fuzzy set F4 is defined as follows, $\mu_{\mathrm{F} 4}(\mathrm{a} 4)=\mathrm{t} 1$, hence, $\mathrm{F} 4$ $=\{(\mathrm{a} 4, \mathrm{t} 1)\}$.

ASA5: Now, the fuzzy operations such as fuzzy set intersection (minimum) and union (maximum) taking three fuzzy membership functions at a time out of total four fuzzy membership functions[Fig. 3]; the four different values of each fuzzy operation such as fuzzy set intersection or union are obtained as mentioned below:

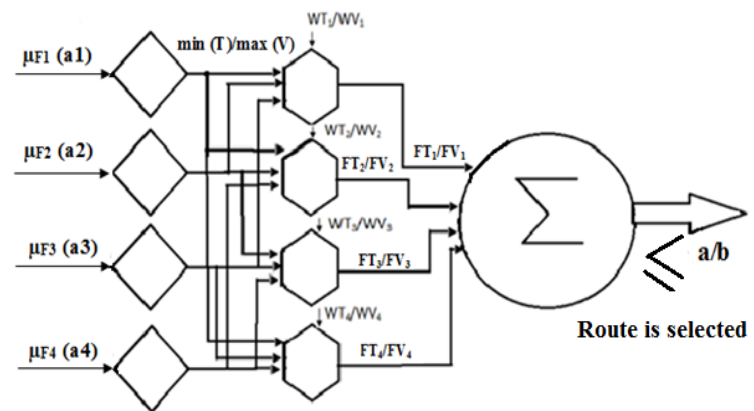

Fig.3. Block diagram of the fuzzy neural network for Modified AODV (Ai-dqAODV) Routing Protocol[11]

ASA6: For ascertaining the best or the optimum route under AODV routing protocol, fuzzy neural network algorithm on the results of the fuzzy operations have been applied.

Different weightages to these fuzzy operations (intersection and union) are imposed and these weightages are assigned by altering different values in practical examples and the best values are considered.

$\mathrm{WT}_{1}: \mathrm{WT}_{2}: \mathrm{WT}_{3}: \mathrm{WT}_{4}=0.5: 0.45: 0.42: 0.4$

$\mathrm{WV}_{1}: \mathrm{WV}_{2}: \mathrm{WV}_{3}: \mathrm{WV}_{4}=0.9: 0.85: 0.83: 0.8$

The values of the fuzzy operations are multiplied by the corresponding weightages for computing the optimum or the final values, i.e.,

$\mathrm{FT}_{1}: \mathrm{FT}_{2}: \mathrm{FT}_{3}: \mathrm{FT}_{4}=\mathrm{T}_{1} \times \mathrm{WT}_{1}: \mathrm{T}_{2} \times \mathrm{WT}_{2}: \mathrm{T}_{3} \times$ $\mathrm{WT}_{3}: \mathrm{T}_{4} \times \mathrm{WT}_{4}=0.5 \mathrm{~T}_{1}: 0.45 \mathrm{~T}_{2}: 0.42 \mathrm{~T}_{3}: 0.4 \mathrm{~T}_{4}$

$\mathrm{FV}_{1}: \mathrm{FV}_{2}: \mathrm{FV}_{3}: \mathrm{FV}_{4}=\mathrm{V}_{1} \times \mathrm{WV}_{1}: \mathrm{V}_{2} \times \mathrm{WV}_{2}: \mathrm{V}_{3} \times$ $\mathrm{WV}_{3}: \mathrm{V}_{4} \times \mathrm{WV}_{4}=0.9 \mathrm{~V}_{1}: 0.85 \mathrm{~V}_{2}: 0.83 \mathrm{~V}_{3}: 0.8 \mathrm{~V}_{4}$

ASA7: All the final values of a particular fuzzy operation are defuzzified by a defuzzifying function. Defuzzification is done by the Composite Maxima method, i.e., $\max \left(\mathrm{FT}_{1}, \mathrm{FT}_{2}, \mathrm{FT}_{3}, \mathrm{FT}_{4}\right)=\mathrm{a}$, and $\max \left(\mathrm{FV}_{1}\right.$, $\left.\mathrm{FV}_{2}, \mathrm{FV}_{3}, \mathrm{FV}_{4}\right)=\mathrm{b}$.

ASA8: The fuzzy-neural rule on the results of the final defuzzified outputs are determined according to examine different values on the practical examples, and then the best suited values are taken.

Thus as per fuzzy neural rule, if $\mathrm{a} \leq 0.21$, and $\mathrm{b} \leq 0.54$ both satisfies, then it ensures that the route is the best route under M-AODV protocol; otherwise, not. Then the data from the other available routes are to be tested accordingly. Here the value of TTL can be optimized by getting the best route immediately. The block diagram of the fuzzy neural network in selecting the best route under Modified AODV protocol is described in Fig. 1.

\section{Implementation Results and Discussion}

Now applying fuzzy-neural rule, $\max \left(\mathrm{FT}_{1}, \mathrm{FT}_{2}, \mathrm{FT}_{3}, \mathrm{FT}_{4}\right)$ $=0.175$, i.e., $\leq 0.21$ and $\max \left(\mathrm{FV}_{1}, \mathrm{FV}_{2}, \mathrm{FV}_{3}, \mathrm{FV}_{4}\right)=$ 0.4335 , i.e., $\leq 0.54$, therefore, the route detected under MAODV scheme is accepted and may be used for traffic (data) flow. Thus, TTL must possess the least value, as the best route is obtained.

\subsection{Simulation}

In this study, we used NCTUns-6.0[12] for simulation. We have chosen this simulator because,

- Highly integrated and professional GUI environment.

- Support for various network protocols.

- Support for various important network.

- Same configuration and operations as for real life networks.

- High simulation speed and repeatable simulation result.

- High fidelity simulation results.

\subsubsection{Performance metrics}

Different performance metrics are used to check the performance of routing protocols in various network environments. In our study we have selected throughput and packet drop to check the performance of VANET routing protocols against each other. The reason for the selection of these performance metrics is to check the performance of routing protocols in highly mobile environment of VANET. Moreover, these performance metrics are used to check the effectiveness of VANET routing protocols i.e. how well the protocol deliver packets and how well the algorithm for a routing protocol performs in order to discover the route towards destination. The selected metrics for routing protocols evaluation are as follows $[13,14]$.

\section{- Throughput}

Throughput is the average number of successfully delivered data packets on a communication network or network node. In other words throughput describes as the total number of received packets at the destination out of total transmitted packets [13]. Throughput is calculated in bytes/sec or data packets per second. The simulation result for throughput in NCTUns6.0 shows the total received packets at destination in $\mathrm{KB} / \mathrm{Sec}$, mathematically throughput is shown as follows:

$$
\left.T_{s}=\left(P_{k} * Z\right) / T_{h} \text { (bytes } / \text { sec }\right)
$$

$P_{k}$ : Total number of received packets at destination

$T_{s}:$ Total simulation time

$Z$ : packet size

$T_{h}$ : Throughput

\section{- Packet Drop}

Packet drop shows total number of data packets that could not reach destination successfully. The reason for packet drop may arise due to congestion, faulty 
hardware and queue overflow etc. Packet drop affects the network performance by consuming time and more bandwidth to resend a packet. Lower packet drop rate shows higher protocol performance.

\section{-Collision}

The Collision of data packet is the number of packets collides to each other due to congestion. It affects the performance directly on the bandwidth. Lower packet collision rate shows higher protocol performance.

\subsection{Simulation scenario:}

We have taken a mess structured scenario (city scenario of New Delhi[15][Fig 4]) as it was earlier studied, where it gives best performance among other type of city scenario of AODV routing algorithm[13,14] ) as our proposed algorithm for routing based on AODV, for dense traffic.

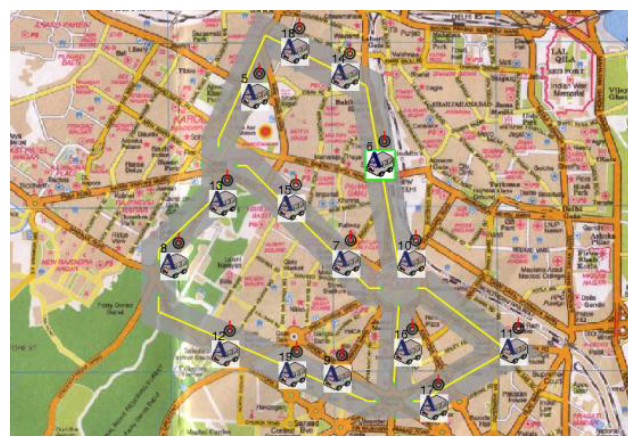

Fig4: Testing Scenario[15]

\subsection{Testing parameters:}

We have taken the simulation parameters for different routing algorithems in NCTUns simulators are as shown in Table 1 and 2.

Table 1: AODV and dqAODV[7] testing parameters

\begin{tabular}{|c|c|}
\hline Parameter & Settings \\
\hline Transmission mode & TCP/IP \\
\hline Lane Width & $20 \mathrm{~m}$ \\
\hline Simulation time & $400 \mathrm{sec}$ \\
\hline RTS threshold & $3000 \mathrm{bytes}(\mathbf{O})$ \\
\hline The car profile (Taken five) & $\begin{array}{c}18 \mathrm{~km} / \mathrm{H}, 36 \mathrm{~km} / \mathrm{H}, \\
50 \mathrm{~km} / \mathrm{H}, 60 \mathrm{~km} / \mathrm{H}, 80 \mathrm{~km} / \mathrm{H}\end{array}$ \\
\hline Number of lane & 2 \\
\hline The protocol & AODV, dqAODV \\
\hline $\begin{array}{c}\text { standard used for each } \\
\text { vehicular node }\end{array}$ & IEEE $802.11 \mathrm{~b}$ \\
\hline $\begin{array}{c}\text { cars are selected for three } \\
\text { different scenarios }\end{array}$ & $10,15,20,25$ (D) \\
\hline Transmission power used & $15 \mathrm{dbm} \mathbf{( P )}$ \\
\hline TTL & $\mathbf{7 ( T )}$ \\
\hline Frequency Channel & $\mathbf{3}$ \\
\hline Hello interval & $\mathbf{1 0 0 0}$ \\
\hline Route Timeout & $\mathbf{3 0 0 0}$ \\
\hline Hello loss & $\mathbf{2}$ \\
\hline Link Bandwidth & $\mathbf{1 1 d b}$ \\
\hline
\end{tabular}

Table 2: ai-dqAODV testing parameters

\begin{tabular}{|c|c|}
\hline Parameter & Settings \\
\hline Transmission mode & TCP/IP \\
\hline
\end{tabular}

\begin{tabular}{|c|c|}
\hline Lane Width & $20 \mathrm{~m}$ \\
\hline Simulation time & $400 \mathrm{sec}$ \\
\hline RTS threshold & $4000 \mathrm{bytes}(\mathbf{O})$ \\
\hline The car profile (Taken five) & $\begin{array}{c}18 \mathrm{~km} / \mathrm{H}, 36 \mathrm{~km} / \mathrm{H}, 50 \mathrm{~km} / \mathrm{H}, \\
60 \mathrm{~km} / \mathrm{H}, 80 \mathrm{~km} / \mathrm{H}\end{array}$ \\
\hline Number of lane & 2 \\
\hline The protocol & Ai-dqAODV \\
\hline $\begin{array}{c}\text { standard used for each } \\
\text { vehicular node }\end{array}$ & IEEE $802.11 \mathrm{~b}$ \\
\hline $\begin{array}{c}\text { cars are selected for three } \\
\text { different scenarios }\end{array}$ & $10,15,20,25$ (D) \\
\hline Transmission power used & $7 \mathrm{dbm}(\mathbf{P})$ \\
\hline TTL & $\mathbf{3 ( T )}$ \\
\hline Frequency Channel & $\mathbf{2}$ \\
\hline Hello Interval & $\mathbf{2 0 0 0}$ \\
\hline Route Timeout & $\mathbf{4 0 0 0}$ \\
\hline Hello loss & $\mathbf{4}$ \\
\hline Link Bandwidth & $\mathbf{7 d b}$ \\
\hline
\end{tabular}

\subsection{Results:}

3.4.1 Collision graph

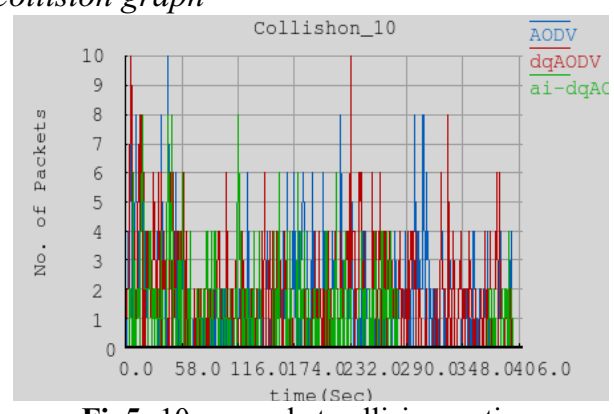

Fig5: 10 car packet collision vs time

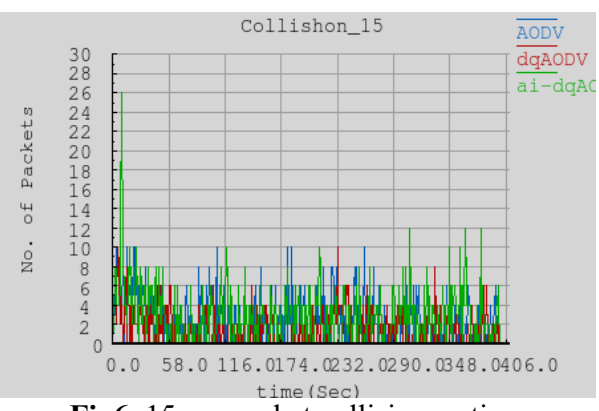

Fig6: 15 car packet collision vs time

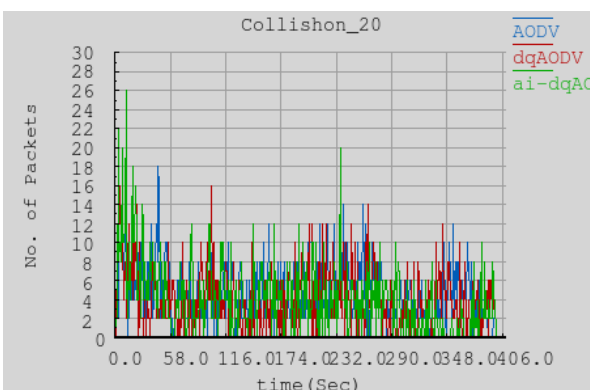

Fig7: 20 car packet collision vs time 


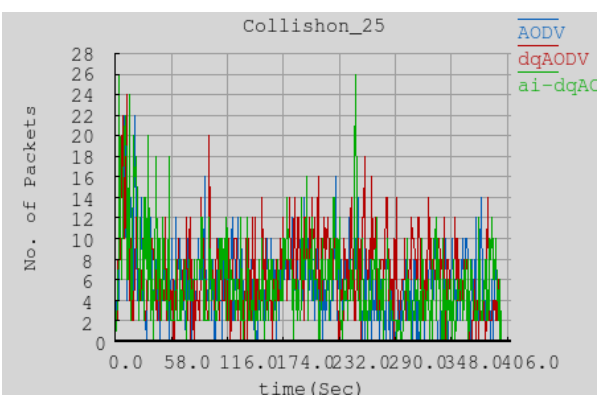

Fig8: 25 car packet collision vs time

\subsubsection{Drop graph}

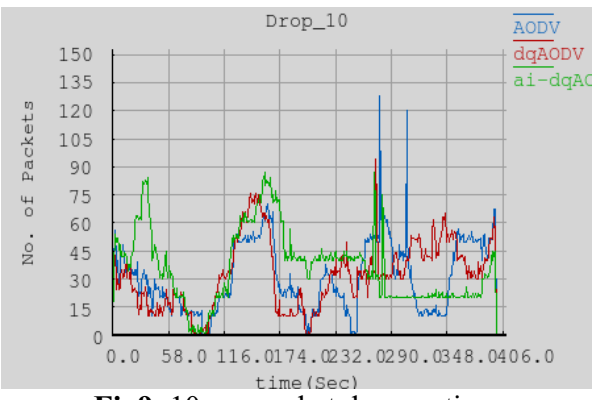

Fig9: 10 car packet drop vs time

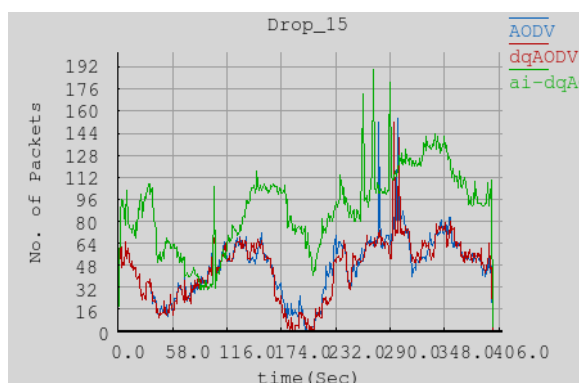

Fig10: 15 car packet drop vs time

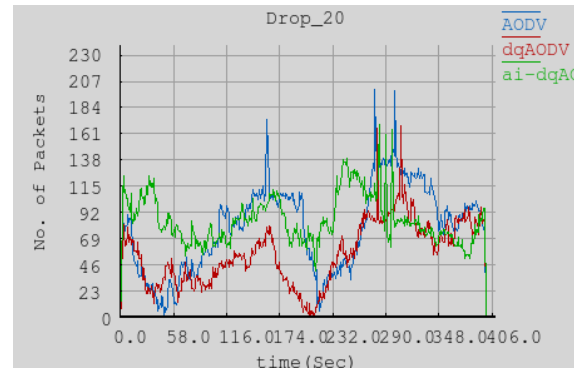

Fig11: 20 car packet drop vs time

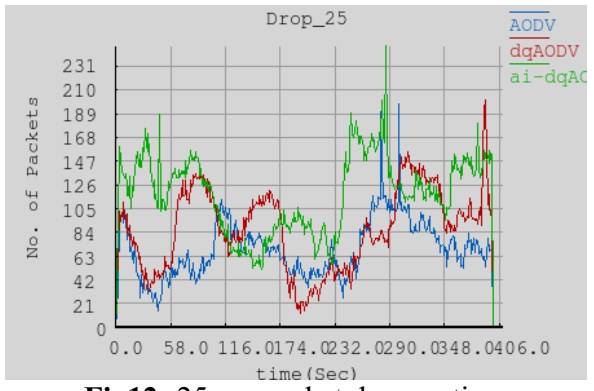

Fig12: 25 car packet drop vs time

\subsubsection{Throughput graph}

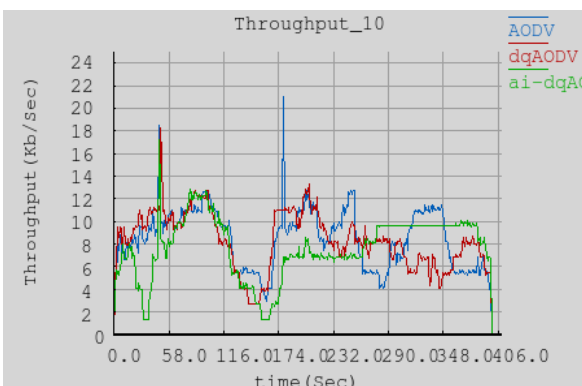

Fig13: 10 car packet throughput vs time

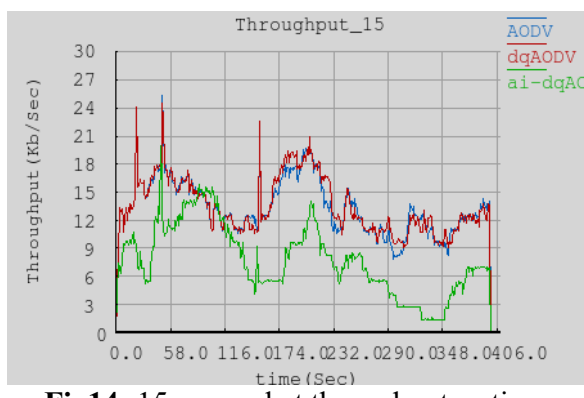

Fig14: 15 car packet throughput vs time

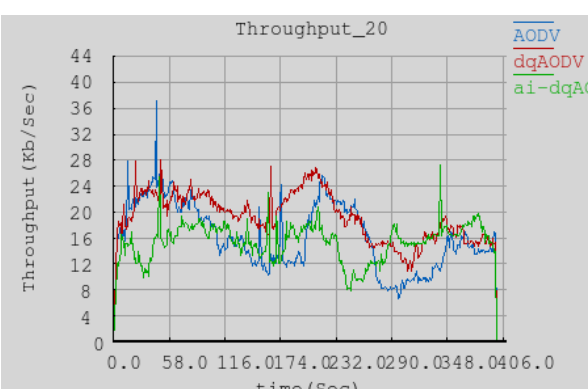

Fig15: 20 car packet throughput vs time

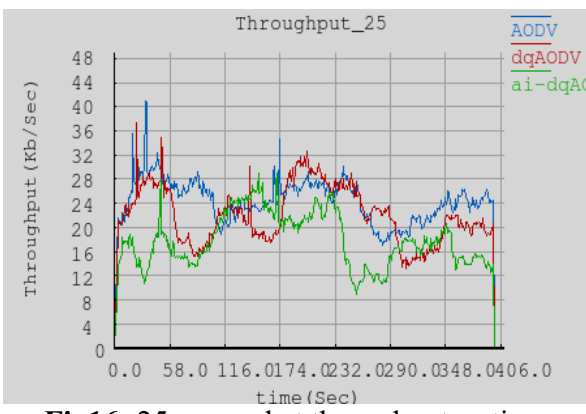

Fig16: 25 car packet throughput vs time

We found the packet in collide is slightly worst in dqAODV than AODV or ai-dqAODV [Fig 5-8]. It causes due to less packet inject in the network of ai-dqAODV. It indicate our proposal of optimization in parameter using neural network is works. Now drop of packets is almost same when car density is low(10) [Fig-9]. But, when car density is higher, the packet drop is considerable high in ai-dqAODV [Fig 10-12]. It indicates some of the routing parameters, like transmission power, etc should be tuned to increase further. Finally packet throughput [Fig.13,14,16] is also comparable with dqAODV and AODV except one situation of car density 15[Fig.15].

Therefore we have got a comparable result with AODV and dqAODV in this proposal. It indicates with reduced 
Power(P), Overhead(D), TTL(T) and same distance (D) we got the satisfactory result for less car density. That proves the optimal parameters usage to discover the routing path is successful according to our proposal using neural network for low car density.

\section{Advantages of the Modified AODV Routing Protocol}

This route discovery technique under Modified AODV protocol is the most efficient one due to applying artificial intelligence $[\mathrm{AI}]$ in advanced stage, i.e., fuzzy neural network used. Also it does not require any further information to supply by the source (host) node while making a call. So it is a unique one. The route is determined by the essential attributes or parameters of the AODV protocol. No cryptography algorithm or any complex functions are applied. This Modified AODV protocol technique ensures the fastest best route discovery.

\section{Conclusions}

In this paper we have proposed to determine the best route from the source node to the destination node through several intermediate nodes using fuzzy neural network algorithm in Modified AODV (aiAODV) routing protocol of VANET communications. We further need to optimize the parameter for better result in dense traffic situation Therefore, the stable connections are set up in a VANET communications by implementing a fast and easy routing techniques like artificial intelligence based Modified AODV routing protocol in the VANET system. There are many variants of routing protocols for VANET transmission have been proposed, those are basically the modified forms of MANET routing protocols. This Modified AODV routing protocol using fuzzy neural network algorithm for the best route searching in VANET is fantastic workable in a real time basis.

\section{References}

1. B. Das, and Dr.U. Roy, "Secured Geocast Routing in VANET (Vehicular Ad-Hoc Network) with two Stage Efficient Communication Protocol", International Journal of Computer Applications (IJCA), Vol. - 53, No. - 12, September 2012, pp 34-38, ISBN : 973-93-80870-40-8.

2. B. Das, S. Misra, Dr.U. Roy, and Mohammad S. Obaidat, "Dynamic Relay Selection for MAClevel Retransmission in Vehicular Ad Hoc Networks," Global Telecommunications Conference (GLOBECOM 2013), 2013 IEEE , 913 Dec. 2013, Atlanta, US.

3. B. Das and Dr.U. Roy, Cooperative Quantum Key Distribution for Cooperative Service-Message Passing in Vehicular Ad Hoc Networks, International Journal of Computer Applications, ISSN 0975 8887, Volume 102, Number 16, pp 37 42, September 2014.

4. RFC of AODV,DSR: www.ietf.org/rfe/rfc3561.txt, www.ietf.org/rfc/rfc4728.txt
5. S. Saha,Dr. U. Roy, Dr. D.D. Sinah, Performance Analysis of VANET Scenario in Ad-hoc Network by NCTUns Simulator, INTERNATIONAL CONGRESS On "Innovative Trends in Information Technologies and Computing Sciences for Competitive World Order" (ITITCSCWO - 2013), 2-3 March, 2013, New Delhi, JNU and followed by IJICT (ISSN 09742239) vol-3, number 7 , pp575-581.

6. "Classification of Ad Hoc Routing Protocols"Petteri Kuosmanen, Finnish Defence ForcesNaval Academy,Helsinki, Finland petteri.kuosmanen@mil.fi

7. S. Saha,Dr. U. Roy, Dr. D.D. Sinah, "AODV ROUTING PROTOCOL MODIFICATION WITH DQUEUE(dqAODV) FOR VANET CITY SCENARIOS" at ICHPCA-2014, Bhubaneswar, India, pp 1-6, IEEE Xplore Digital Library, December 22-24, 2014, ISBN : 978-1-4799-59570 ;

8. E. Rich, K. Knight, and S. B. Nair, Artificial Intelligence, $3^{\text {rd }}$ Edition, Tata McGraw Hill Education Private Ltd., 2010.

9. V.Novak, J.Mockor, and I. Perfilieva, Mathematical Principles of Fuzzy Logic, Kluwer Academic Publisher, 2006.

10. J. Yan, M. Ryan, and J. Power, Using Fuzzy Logic: Towards Intelligent Systems, Prentice-Hall of India Pvt. Ltd., 1995.

11. P. K. Bhattacharjee, S. Roy, R. K. Pal, Mutual Authentication Technique with Four Entities Using Fuzzy Neural Network in 4-G Mobile Communications, IOSR Journal of Computer Engineering (IOSR-JCE), PP 69-76,2015

12. NCTUns6.0 protocol developer manual; http://elearning.vtu.ac.in/15/ENotes/NW\%20prog $\% 201$ ab/NCTUns\%20Manual.pdf

13. S.Saha, Dr. U. Roy, Dr. D.D. Sinah, VANET Simulation in diffrent Indian City Scenario, In Conference On "Recent Global Trends in Electronic Communication Engineering, Power and Control" (ECEPC-2013), 7-8 September, 2013, New Delhi ,JNU.

14. S. Saha,Dr. U. Roy, Dr. D.D. Sinah, Performance comparison of various Ad-Hoc routing protocols of VANET in Indian City scenario, AIJRSTEM 14-126 ,ISSN (Online): 2328-3580 , pp49-54, March 7, 2014.

15. www.mapsofindia.com 